\title{
ANÁLISE DE ESTUDOS NACIONAIS E INTERNACIONAIS NO CAMPO FORMAÇÃO INICIAL DE PROFESSORES.
}

\author{
Michelle Tosta Prates, Renata Portela Rinaldi \\ Universidade Estadual Paulista - UNESP, Pedagogia. Presidente Prudente, SP E-mail: michelle.tosta85@gmail.com. \\ Agência de fomento: PIBIC/CNPq
}

\begin{abstract}
RESUMO
A formação inicial de professores tem sido discutida em diversos contextos e, atrelado a este processo, princípios que norteiam o desenvolvimento e a construção de saberes docentes. 0 objetivo deste estudo foi analisar o que revelam as pesquisas sobre a formação inicial de professores no Brasil e na Inglaterra, no período de 2011 a 2016. A metodologia utilizada foi a pesquisa bibliográfica, usando as publicações de um periódico britânico e periódicos brasileiros na área da Educação com estrato $A 2$, e da análise sistemática para discussão dos resultados. Nos resultados foram identificados 145 artigos no exterior e 912 nos periódicos brasileiros. Em geral, o assunto mais recorrente foi a formação inicial de professores, desenvolvimento profissional da docência e aprendizagem da docência. Concluímos que no Brasil e no exterior, há avanços nas pesquisas sobre o assunto, porém é preciso ampliar e evoluir sobre as vertentes que abrangem o tema formação de professores.

Palavras-chave: Formação de professores, formação inicial de professores, análise sistemática, desenvolvimento profissional da docência, aprendizagem da docência.
\end{abstract}

\section{ANALYSIS OF NATIONAL AND INTERNATIONAL RESEARCH ON INITIAL TEACHER EDUCATION.}

\begin{abstract}
Initial teacher education has been studied in light of principles that guide the development and construction of teacher knowledge in several contexts. This study aimed to analyze the research on pre-service teacher education carried out in Brazil and England from 2011 to 2016. The study methodology comprised a literature review of journal articles published in England and Brazil (ranked as A2). There were identified 145 and 912 articles in English and Brazilian journals, respectively, which were then analyzed through systematic review. On the whole, the most recurring topics were initial teacher education, teacher professional development, and teacher learning. It may be concluded that research on the subject has made significant progress both in Brazil and abroad; however, there is still the need to expand and advance knowledge along the lines that address the topic of teacher education.

Keywords: Teacher education; Initial teacher education; Systematic analysis; Teacher professional development; Teacher learning.
\end{abstract}




\section{INTRODUÇÃO}

A formação inicial de professores tem sido discutida nas últimas décadas em diversos contextos, atrelando a este processo princípios que norteiam o desenvolvimento e a construção de saberes docentes. Estes princípios refletem diretamente na futura atuação do professor e principalmente, na aprendizagem dos estudantes. Além disso, Gatti e Barreto (2009) apontam que um dos grandes problemas no Brasil hoje, na área da Educação, é a pouca atratividade da profissão docente e a baixa vocação para a área, que se justificam, entre outros fatores, pela desvalorização social da profissão e pela instabilidade na carreira, e que dizem respeito ao seu estatuto social e profissional.

Para Rinaldi e Cardoso (2012, p. 1):

Pensar a formação inicial de professores na atualidade se configura um grande desafio que tem sido objeto de múltiplas análises que indicam as lacunas e severos problemas associados ao modo como essa formação é concretizada. Isso se dá não apenas por conta das diferentes propostas metodológicas que nos podem servir de referência, mas também, devido ao modo como o conhecimento, seus conteúdos formativos e as estruturas curriculares dos cursos de Licenciatura e das escolas de modo geral, são modificadas e, sobretudo, à velocidade em que tais mudanças muitas vezes ocorrem.

Numa primeira fase do estudo, em que Prates e Rinaldi (2015) analisaram as produções nacionais, dos periódicos qualificados no estrato A1, e internacional, a partir do periódico Teaching and Teacher Education, verificaram que

o impacto das pesquisas sobre o modo como as autoridades determinam as políticas sobre o assunto [formação de professores] é muito pequeno, ou seja, estas pesquisas não são realmente levadas em consideração no momento da definição de políticas educacionais tanto no cenário nacional como no internacional. (PRATES; RINALDI, 2015, p. 1272).

Para a segunda fase da pesquisa, as autoras realizaram a análise de produções nacionais sobre o tema, em periódicos qualificados no estrato $A 2$, e no cenário internacional, realizaram a análise das produções a partir do periódico britânico Journal of Teacher Education.

A opção por priorizar a apresentação dos resultados obtidos na segunda fase da pesquisa decorre do fato de termos obtido um grande volume de dados e dos resultados parciais apresentados por Prates e Rinaldi (2015). Posto isso, para o presente artigo, propõe-se refletir sobre o que revelam as pesquisas sobre a de formação inicial de professores no Brasil e no exterior e identificar os caminhos que já foram percorridos com vistas a uma formação que atenta às demandas do cotidiano escolar e dos desafios da contemporaneidade.

\section{METODOLOGIA}

A pesquisa caracteriza-se como de natureza qualitativa, do tipo pesquisa bibliográfica. Esse tipo de estudo pode ser definido como "[...] um conjunto ordenado de procedimentos de busca por soluções, atento ao objeto de estudo, e que, por isso, não pode ser aleatório" (MINAYO, 2002, p. 17). Ela se caracteriza como um procedimento metodológico de caráter exploratório-descritivo. Ou seja, o passo inicial para concretização deste tipo de pesquisa consiste na realização de uma revisão bibliográfica do tema estudado, buscando uma problematização a partir das referências de investigações anteriores.

Para tanto, na presente pesquisa foram analisadas as publicações do periódico britânico Journal of Teacher Education considerando o cenário internacional e, no cenário nacional, foram 
analisadas as produções dos periódicos brasileiros, na área da Educação e qualificados no estrato A2. O período de tempo delimitado para a coleta de dados foi de 2011 a 2016. Os unitermos utilizados foram: formação de professores, formação inicial de professores, estágio supervisionado, prática de ensino, desenvolvimento profissional da docência, aprendizagem da docência, aprendizagem profissional da docência, inclusão e PIBID.

No caso da base de dados internacional foram analisadas as produções do periódico britânico Journal of Teacher Education, em que foram identificados no período um total de 145 artigos que tratavam direta ou indiretamente do tema investigado. Cabe ressaltar, que o acesso aos artigos é pago e, portanto, nos restringimos a análise dos resumos das produções. Para os periódicos brasileiros, acessamos o Sistema Integrado da Capes (Webqualis) e geramos na seção "Por qualificação/ Área de avaliação" uma listagem com os periódicos da área da Educação com estrato A2. A partir da listagem foi obtido um total de 77 periódicos. Destes, excluímos aqueles periódicos internacionais e focamos apenas nos veículos nacionais disponíveis on-line. Com este processo de tratamento inicial, tivemos 33 periódicos selecionados para análise. Ao realizarmos o procedimento de acesso a cada um deles foram identificados 912 artigos vinculados ao tema da investigação.

Para a análise dos dados utilizamos o procedimento de análise sistemática (SAMPAIO; MANCINI, 2007), a fim de descrever como tem sido implementada as iniciativas de formação inicial de professores tanto no Brasil como no exterior. Esse tipo análise

[...] requer uma pergunta clara, a definição de uma estratégia de busca, o estabelecimento de critérios de inclusão e exclusão dos artigos e, acima de tudo, uma análise criteriosa da qualidade da literatura selecionada. 0 processo de desenvolvimento desse tipo de estudo de revisão inclui caracterizar cada estudo selecionado, avaliar a qualidade deles, identificar conceitos importantes, comparar as análises estatísticas apresentadas e concluir sobre o que a literatura informa em relação a determinada intervenção, apontando ainda problemas/questões que necessitam de novos estudos (SAMPAIO; MANCINI, 2007, p. 84).

\section{RESULTADOS}

$\mathrm{Na}$ análise das produções internacionais foram identificados 145 artigos no período. Alguns resultados que envolvem a temática da formação inicial de professores podem ser observados no Quadro 1.

Quadro 01. Temas encontrados nos artigos do periódico britânico.

\begin{tabular}{|c|c|c|c|c|c|c|c|}
\hline Assuntos & $\mathbf{2 0 1 1}$ & $\mathbf{2 0 1 2}$ & $\mathbf{2 0 1 3}$ & $\mathbf{2 0 1 4}$ & $\mathbf{2 0 1 5}$ & $\mathbf{2 0 1 6}$ & Total \\
\hline Aprendizagem da docência & 6 & 6 & 4 & 3 & 7 & 1 & $\mathbf{2 7}$ \\
\hline $\begin{array}{c}\text { Desenvolvimento profissional } \\
\text { da docência }\end{array}$ & 12 & 5 & 7 & 5 & 7 & 2 & $\mathbf{3 8}$ \\
\hline Formação inicial & 4 & 7 & 14 & 8 & 4 & 6 & $\mathbf{4 3}$ \\
\hline Parceria U-E/ estágio & 2 & 0 & 0 & 1 & 2 & 0 & $\mathbf{5}$ \\
\hline Políticas educacionais & 2 & 3 & 1 & 4 & 5 & 3 & $\mathbf{1 8}$ \\
\hline Práticas de ensino & 2 & 1 & 2 & 3 & 4 & 2 & $\mathbf{1 4}$ \\
\hline
\end{tabular}

Fonte: Sistematização das autoras.

Percebemos uma oscilação das investigações sobre o tema no período. Dos artigos estudados é possível observar que as maiores frequências dos temas estão nos descritores: formação inicial $(23,6 \%)$, desenvolvimento profissional da docência $(26,2 \%)$ e aprendizagem da docência $(18,6)$. A temática que compareceu com a menor frequência $(3,5 \%)$ foi a parceria entre a 
universidade e a escola e estágio supervisionado. Em geral, ao avaliarmos os trabalhos, foi possível perceber que a maioria das universidades em que os pesquisadores autores estão vinculados encontra-se nos Estados Unidos, e as universidades da Inglaterra, onde se localiza o periódico, o número foi bastante pequeno.

Quando analisamos as produções nacionais, identificamos nos periódicos avaliados no estrato A2 um total de 912 artigos que tratavam direta ou indiretamente do tema investigado. As principais temáticas abordadas nas produções podem ser observadas no Quadro 02.

Quadro 02. Temas encontrados nos artigos dos periódicos com estrato A2.

\begin{tabular}{|l|c|c|c|c|c|c|c|}
\hline \multicolumn{1}{|c|}{ Assuntos } & $\mathbf{2 0 1 1}$ & $\mathbf{2 0 1 2}$ & $\mathbf{2 0 1 3}$ & $\mathbf{2 0 1 4}$ & $\mathbf{2 0 1 5}$ & $\mathbf{2 0 1 6}$ & Total \\
\hline $\begin{array}{l}\text { Formação inicial de } \\
\text { professores/ Formação de } \\
\text { professores }\end{array}$ & 85 & 92 & 69 & 75 & 84 & 20 & $\mathbf{4 2 5}$ \\
\hline Estágio supervisionado & 4 & 7 & 1 & 6 & 7 & 1 & $\mathbf{2 6}$ \\
\hline Prática de ensino profissional & 18 & 6 & 10 & 15 & 16 & 3 & $\mathbf{6 8}$ \\
\hline $\begin{array}{l}\text { Desenvolvimento } \\
\text { da docência }\end{array}$ & 17 & 18 & 8 & 17 & 8 & 6 & $\mathbf{7 4}$ \\
\hline Aprendizagem da docência & 0 & 0 & 0 & 1 & 1 & 3 & $\mathbf{5}$ \\
\hline PIBID & 23 & 24 & 20 & 17 & 20 & 3 & $\mathbf{1 0 7}$ \\
\hline Inclusão escolar & & & & & & & \\
\hline
\end{tabular}

Fonte: Sistematização das autoras.

Verificou-se que a maior parte dos trabalhos $(46,60 \%)$ se volta à temática da formação inicial de professores/ formação de professores. Apenas 2,85\% trata sobre estágio supervisionado, $22,69 \%$ indica as práticas de ensino, $7,45 \%$ relata acerca do desenvolvimento profissional da docência e $8,11 \%$ da aprendizagem da docência. Somente $0,54 \%$ versa sobre o PIBID e 11,73\% se volta para a inclusão escolar. Percebe-se nos artigos que os autores não deram maior atenção ao estágio e ao PIBID, sendo a atenção maior para a formação de professores, práticas de ensino e inclusão escolar.

De forma geral, o assunto mais recorrente tanto no Brasil como no exterior, foi a formação inicial de professores. O desenvolvimento profissional da docência e aprendizagem da docência também foram temas contemplados nos artigos. Porém as práticas de ensino foram pouco exploradas no cenário internacional e quanto ao nacional foi um dos temas mais discutidos.

\section{DISCUSSÃO}

No Brasil, percebemos nos periódicos analisados que há falta de pesquisas que discutam o tema PIBID, desenvolvimento e aprendizagem da docência e estágio supervisionado. Os estudos encontrados não aprofundam nos temas, apenas discutem superficialmente e apresentam algumas experiências pontuais ou de revisão sobre o tema.

Sobre as tendências das pesquisas no campo da formação docente, verifica-se que no início dos anos de 1990, o foco principal era a formação inicial do professor, analisando-se os cursos de licenciatura e a escola normal. Já nos anos 2000, esse foco mudou drasticamente, voltando-se mais para a identidade e profissionalização docente, tendo como centro o professor, suas opiniões, saberes e práticas. Na segunda década dos anos 2000 podemos identificar algumas preocupações que envolvem a prática de ensino como uma preocupação latente dos pesquisadores.

A partir da análise das teses e dissertações, André (2011) nos aponta importantes lacunas no campo de pesquisa sobre formação de professores no Brasil. Primeiramente, ela ressalta a baixa qualidade das pesquisas brasileiras: há uma grande fragilidade teórica, metodológica, 
epistemológica e procedimental nas pesquisas. O pesquisador é muito malformado e isto acaba comprometendo a qualidade das pesquisas. Além disso, as pesquisas em geral não apontam resultados, ou seus resultados são muito imprecisos. A autora nos diz ainda, que o conhecimento revelado pelas pesquisas é parcelado e incompleto.

Outro ponto destacado pela autora como lacuna no campo é o fato de que, com o deslocamento do foco das pesquisas nos anos 2000, a pesquisa sobre formação inicial foi muito reduzida, fato preocupante, pois ainda há muito a ser conhecido sobre a formação inicial dos docentes. No entanto, nas produções analisadas, foi encontrado um bom número de trabalhos que versam direta ou indiretamente sobre a formação inicial de professores, suas vertentes, conceitos, e importância no desenvolvimento do futuro professor.

Analisando os materiais produzidos pela autora, é possível perceber que o campo de pesquisa sobre formação de professores no Brasil já se encontra consolidado e vem recebendo um interesse crescente, gerando avanços nas pesquisas.

Segundo Whitty, Power e Halpin (1998) apud Lüdke et al (1999) na Inglaterra, as reformas educacionais são refletidas através de lutas entre diferentes visões do trabalho docente. Nunes (1996) apud Lüdke et al (1999) aponta críticas ao modelo de professor que deseja se formar, entre elas:

a) o professor universitário que contribui para a formação deveria ser valorizado por sua competência para o ensino, sua participação em pesquisas, sua liderança, sua postura crítica e sua capacidade de análise da formação docente e da educação como um todo, e não por uma experiência recente em escola; b) a proposta de reformulação dos cursos foi feita sem qualquer evidência de sua necessidade, assim como sem qualquer estudo prévio que a fundamentasse; c) valoriza-se mais um professor capaz de dominar uma lista de competências específicas do que um professor competente, entendendo-se competência, nesse caso, de modo bem mais amplo. (1999, p. 290)

A partir das críticas "pode-se supor que o propósito maior do governo inglês, ao reformular a formação docente, seja tornar visível alguma preocupação com a educação em época de escassez de recursos" (LÜDKE; MOREIRA; CUNHA, 1999, p. 290). Com isso, vem o temor de que uma queda nos salários dos professores, diminui também a qualidade da educação ao invés de progredi-la. Dessa forma, conclui-se que as reformas educacionais no país não têm beneficiado o desenvolvimento do poder tanto dos docentes como dos discentes.

Muitas vezes o papel das escolas de ensino fundamental pode parecer chamativo, porém há problemas quanto ao financiamento dos cursos, na carreira e nos salários dos professores. "Entre nós, a parceria com as escolas envolveria ainda o problema de expor os estagiários à vivência de realidades escolares cujas limitações são constrangedoras para seus próprios professores" (LÜDKE; MOREIRA; CUNHA, 1999, p. 295).

Quanto ao salário, há uma distância considerável entre os professores do ensino fundamental e os professores do ensino superior. Em outros países, a aproximação desses salários, garante a possibilidade de desenvolvimento na profissão docente.

Outro aspecto ressaltado pelos autores é "a ameaçada autonomia do professor, perante as crescentes medidas de controle de seu trabalho e a estimulação da participação das famílias e das comunidades na vida da escola, e o importante papel formativo que poderia ser desempenhado por sindicatos e associações da categoria docente" (LÜDKE; MOREIRA; CUNHA, 1999, p. 295).

Por fim, é apontado que a formação de professores é geralmente considerada uma função de pouca importância quando comparada com outras atividades na universidade, principalmente 
a pesquisa, sendo esta última, algo de grande valor na academia e na melhoria da formação de professores.

\section{CONCLUSÃO}

Ao considerar os resultados da investigação, e estudos de alguns pesquisadores, pode-se afirmar que a temática da formação de professores, vem ganhando cada vez mais destaque na pesquisa em Educação tanto no país quanto no exterior. Se nos anos 1990 os estudos sobre a formação de professores representavam cerca de $6 \%$ das pesquisas em educação, atualmente, meados da segunda década do século XXI, eles correspondem a cerca de $35 \%$ desta produção. Contudo, o enfoque das investigações prioriza determinados aspectos e, em nossa pesquisa, verificamos que o 'olhar' para a formação inicial tem sido insuficiente nas produções divulgadas nos periódicos analisados.

Para André et al (2010) no Brasil, as reformas educacionais implantadas nos últimos dez anos atribuem ao professor um papel central na melhoria do processo educativo. A formação do docente tornou-se, então, um dos temas mais importantes na agenda das reformas, ou seja, espera-se muito dos cursos de formação inicial de professores.

Alguns desafios precisarão ser enfrentados nesse momento da formação profissional, entre os quais: a revisão dos currículos, o investimento na parceria entre a universidade e a escola como estratégia de aproximação efetiva e produtiva do futuro professor do seu campo futuro de trabalho. Da mesma forma, repensar a formação contínua dos formadores, o desenvolvimento profissional ainda nos cursos de formação inicial e a preparação dos futuros profissionais para lidar com a inclusão e a realidade multicultural, são igualmente desafios que se colocam aos cursos de formação inicial tanto no Brasil quanto no exterior.

A partir dos resultados foi possível notar que os estudos internacionais apontam para iniciativas ainda inexistentes ou bastante raras no cenário nacional, por exemplo, como a construção de programas de mentoria ou indução ainda na formação inicial de futuros professores. Tais iniciativas, auxiliam os pesquisadores a compreender como os estudantes de cursos de licenciaturas aprendem como é aprender a ser professor, tendo a oportunidade de articular teoria e prática, refletir e agir sobre situações reais sob orientação de um professor especialista e bem-sucedido, assim como analisar sobre essas situações e resultados com o apoio do pesquisador e professor da universidade.

Em geral, é possível afirmar que a formação de professores é algo inacabado pois inicia-se antes da formação inicial e o educador está sempre em busca de uma formação contínua, para desenvolver suas competências em seu campo de trabalho. Esse aperfeiçoamento dos profissionais é algo de suma importância, pois visa melhorar o ensino e a qualidade da educação.

\section{REFERÊNCIAS}

ANDRÉ, M. E. D. A. de. et al. O trabalho docente do professor formador no contexto atual das reformas e das mudanças no mundo contemporâneo. Revista Brasileira de Estudos Pedagógicos, Brasília, v. 91, n. 227, p. 122-143, jan./abr. 2010.

ANDRÉ, M. E. D. A. de. Pesquisas sobre formação de professores: tensões e perspectivas do campo. In: FONTOURA, H. A. de.; SILVA, M. (orgs.) Formação de professores, Culturas: Desafios à Pós-graduação em Educação em suas múltiplas dimensões. Rio de Janeiro: ANPEd Nacional, 2011. p. 24-36.

GATTI, B. A.; BARRETO, E. S. S. Professores do Brasil: impasses e desafios. Brasília: Unesco, 2009. 
LÜDKE, M.; MOREIRA, A. F. B.; CUNHA, M. I. da. Repercussões de tendências internacionais sobre a formação de nossos professores. Rev. Educação \& Sociedade, Campinas, v. 20, n. 68, p. 278-298, dez. 1999. https://doi.org/10.1590/S0101-73301999000300014

MINAYO, M. C. Pesquisa Social: teoria, método e criatividade. Petrópolis, Vozes, 2002.

PRATES, M. T.; RINALDI, R. P. Formação inicial de professores: uma análise sistemática da produção nacional e norte americana. Colloquium Humanarum, v. 12, n. Especial, 2015, p. 12651273. ISSN: 1809-8207. https://doi.org/10.5747/ch.2015.v12.nesp.000748

RINALDI, R. P.; CARDOSO, L. C. O estágio supervisionado na formação inicial de professores: aproximações com o contexto escolar. In: Congresso Internacional sobre Profesorado Principiante e Inserción Profesional a la Docencia, 3, Santiago de Chile, 2012.

SAMPAIO, R. F.; MANCINI, M. C. Estudos de revisão sistemática: um guia para síntese criteriosa da evidência científica. Rev. Bras. Fisioter., São Carlos, v. 11, n. 1, p. 83-89, jan./fev. 2007.

TATTO, M. T. Policies for teachers working in the periphery: an international review of the literature. Michigan State University, 1993. 